\title{
Disturbance of inorganic phosphate metabolism in diabetes mellitus: clinical manifestations of phosphorus-depletion syndrome during recovery from diabetic ketoacidosis
}

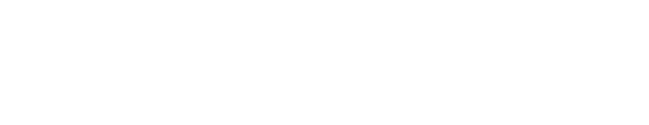

Jørn Ditzel

Hans-Henrik Lervang

Department of Endocrinology, and Center for Prevention of Struma and Metabolic Diseases, Aalborg University Hospital, Aarhus University, Denmark
Correspondence: Hans-Henrik Lervang Department of Endocrinology, Aalborg University Hospital, Aarhus University, 9000 Aalborg, Denmark

Tel +4599 $326 \quad 125$

Fax +45 99326008

Email hhl@rn.dk; jditzel@ofir.dk

\begin{abstract}
The acute effects of intracellular phosphate depletion and hypophosphatemia on organs and tissues in and during recovery from diabetic ketoacidosis (DKA) have been reviewed. When insufficient phosphate and/or oxygen are available for high energy phosphate synthesis, cell homeostasis cannot be maintained and cell integrity may be impaired. The clinical consequences are recognized as occasional cause of morbidity and mortality. Although phosphate repletion has not been routinely recommended in the treatment of DKA, physicians should be aware of these clinical conditions and phosphate repletion in such situations should be considered.
\end{abstract}

Keywords: high energy phosphates, hypoxia, fructose 1,6-diphosphate

\section{Introduction}

The phosphorus-depletion syndrome has been known to veterinary surgeons for many decades. In the 1960s, the phosphorus-depletion syndrome was first described in Man by Bloom and Flinchum, ${ }^{1}$ who also reported a case of muscle weakness and osteomalacia in a patient with excessive ingestion of nonabsorbable antacids containing magnesium-aluminum hydroxides, which limit gastrointestinal absorption of phosphorus. Lotz et $\mathrm{al}^{2}$ presented the effects of experimental phosphorus depletion in three normal volunteers and in three patients with parathyroid dysfunction during prolonged treatment with antacids. They observed a syndrome with hypophosphatemia, increased absorption of skeletal calcium and phosphorus, and clinical symptoms such as debilitation, anorexia, weakness, and bone pain. These reports were followed by more extensive research and reviews. ${ }^{3-5}$

Recently, we have presented the evidence of the occurrence of a paradoxical imbalance in phosphate metabolism from the early onset of diabetes mellitus and have indicated that this imbalance may lead to a reduction of high energy phosphates and tissue hypoxia. These changes take place in cells and tissues in which the entry of glucose is not controlled by insulin and occur particularly in poorly regulated, though ambulatory diabetic patients in whom long-term vascular complications are more likely. ${ }^{6,7}$

In this article, we review the evidence suggesting the role of cellular phosphorus depletion and hypophosphatemia in the development of acute, occasionally lifethreatening complications in hospitalized patients during treatment of diabetic ketoacidosis (DKA). The review is based on a search primarily using Medline (PubMed) and secondarily Embase, as well as information from reference lists. 


\section{Inorganic phosphate and ketoacidosis}

DKA is associated with various degrees of intracellular phosphate depletion, partially because of a shift of phosphorus from the intracellular to the extracellular compartments and because of prolonged and excessive hyperphosphaturia. ${ }^{6}$ During DKA, the plasma inorganic phosphate (Pi) may be normal or even elevated despite intracellular phosphate depletion. Initial treatment with intravenous fluid and insulin allows sudden entry of plasma glucose and phosphate into the insulin-sensitive tissues for cellular phosphorylation, and plasma Pi may be drastically decreased. Riley et $\mathrm{a}^{8}$ demonstrated that insulin-induced hypophosphatemia is dose dependent and significant hypophosphatemia may occur within 30 minutes following administration of insulin. In the clinical situation, "refeeding" hypophosphatemia is usually first recognized at the second day of treatment and may last for a week depending on the degree of intracellular phosphate depletion and the replacement rate of intravenous fluid and insulin. In contrast to plasma $\mathrm{Pi}$, the degree of intracellular phosphate cannot be clinically determined on admission because this parameter depends on the preceding dietary intake of phosphorus, the duration of the ketotic state, and the presence of associated factors, such as stress, infections, and duration of insufficient insulin intake.

Cellular phosphate depletion and associated hypophosphatemia, if severe, may give rise to signs and symptoms from many organ systems and is recognized as a cause of morbidity and mortality in DKA. When insufficient phosphate and oxygen are available for adenosine triphosphate (ATP) synthesis, cell homeostasis cannot be maintained and may result in cell lyses. ${ }^{9}$ Because randomized studies of patients with ketoacidosis on phosphate therapy did not affect the duration of DKA, dose of insulin required to the acidosis, abnormal muscle enzyme levels, glucose disappearance rate, or morbidity and mortality, phosphate therapy is not an essential part of the therapy for DKA in most patients. ${ }^{10-13}$ However, although phosphate repletion is not recommended as an adjuvant in the treatment of DKA, ${ }^{14}$ physicians should be aware of the clinical manifestations to ensure no delay in phosphate repletion in such situations.

\section{Hematological manifestations}

Phosphorus plays an important role in several aspect of cellular metabolism, including ATP synthesis, which is the source of energy for many cellular reactions, and red cell 2,3-diphosphoglycerate (2,3-DPG), which regulates the dissociation of oxygen from hemoglobin. Studies have shown low levels of 2,3-DPG and ATP in red blood cells and the fact that low levels of intraerythrocytic phosphate inhibit whereas high levels stimulate red cell glycolysis. ${ }^{15-17}$ During DKA, the effect of increased hydrogen ions on the oxyhemoglobin dissociation curve (ODC) is balanced by the diminished 2,3-DPG. However, after correction of acidosis, the low 2,3-DPG level shifts the ODC markedly to the left with a corresponding decrease in the ODC $\mathrm{P}_{50}$ (oxygen tension at $50 \%$ oxygen saturation). In close correlation with plasma Pi concentration, it may take up to 1 week for 2,3-DPG to return to an approximately normal level, and the oxygen delivery to tissues will be impaired for the same period (Figure 1). ${ }^{18-20} \mathrm{P}_{50}$ of ODC at in vivo $\mathrm{pH}$ in 10 consecutive cases of ketoacidosis following insulin administration correlated closely with plasma $\mathrm{Pi}(\mathrm{r}=0.80 ; P<0.001)$ and red cell 2,3-DPG $(\mathrm{r}=0.94 ; P<0.001) .{ }^{21}$ This deficient oxygen delivery influences all organs and tissues, although organs with high oxygen demand, such as the renal medulla, brain, retina, pancreas, and heart, may suffer the most.

When red cell ATP is significantly decreased, the erythrocyte membrane becomes rigid, and such erythrocytes may be trapped in the spleen leading to hemolytic anemia. ${ }^{22}$ When ATP levels in the leukocytes are significantly decreased, their phagocytic, chemotactic, and bactericidal activities are reduced. ${ }^{23}$

\section{Neurological manifestations}

Encephalopathy, confusion, seizures, hallucinations, and coma are the clinical signs that may develop during prolonged, severe hypophosphatemia following treatment of DKA. When verified, these symptoms should be promptly treated with intravenous phosphate, which often result in dramatic recovery. ${ }^{24-27}$

\section{Muscular manifestations}

Muscular weakness is a common symptom, and myopathy, even in its more severe form as rhabdomyolysis, may occur. $^{28,29}$ Among 12 consecutively admitted ketoacidotic patients, we found five with asymptomatic hypermyoglobulinemia and elevated creatine kinase isoenzyme MM, characteristic of rhabdomyolysis. ${ }^{29}$ Patients with DKA are invariably dehydrated - often severely - and restoration of fluid and electrolytes is of first priority. In DKA, a remarkable small extraction of oxygen takes place through muscular and cutaneous tissues. ${ }^{18,30}$ Patients with DKA, in addition to dehydration, may also be in a preshock situation, which leads to a considerably increased release of catecholamine, mainly noradrenalin, ${ }^{31}$ and a redistribution of microcirculatory flow. 

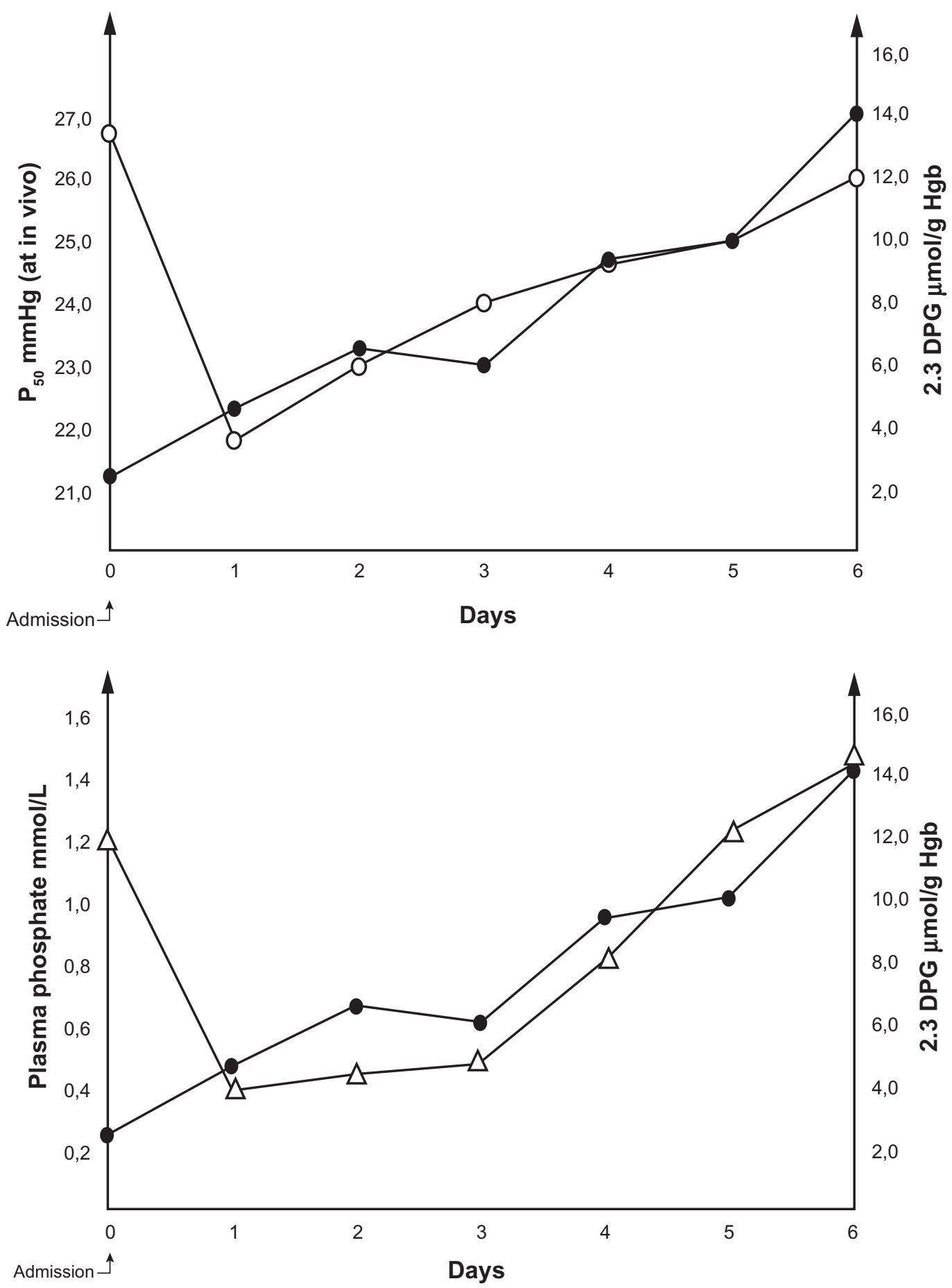

Figure I Pattern of changes in plasma phosphate $(\Delta)$, 2,3-DPG $(\bullet)$, and $\mathrm{P}_{50}$ at in vivo $\mathrm{pH}$ on the oxyhemoglobin dissociation curve $(\circ)$ in a case of diabetic ketoacidosis. Abbreviations: 2,3-DPG, 2,3-diphosphoglycerate; $\mathrm{Hb}$, hemoglobin.

The arterioles in the cutaneous and splanchnic areas may be constricted, and blood flow will be shunted through biomicroscopically observable arteriolar-venular communications (thoroughfare channels; vascular pattern-change II) whereby blood flow bypasses the nutritive capillaries. ${ }^{32}$ The resulting ischemic hypoxia of glucose- and phosphate-starved muscle cells may lead to reduced ATP, resulting in membrane disruption and allowing myoglobin and creatine kinase isoenzyme MM to enter into the circulation.

\section{Myocardial manifestations}

Møller et $\mathrm{al}^{33}$ presented two patients with severe DKA, who showed elevations of the biomarkers troponin $\mathrm{T}$ and creatine kinase $\mathrm{MB}$ and initial electrocardiographic changes 
compatible with myocardial infarction. However, all successive investigations including coronary arteriography were normal. The concentration of plasma Pi was not reported. Hypophosphatemia is known to be associated with low levels of cellular ATP and impairment of human myocardial performance. ${ }^{34,35}$

\section{Pulmonary manifestations}

Acute respiratory failure in DKA patients with severe hypophosphatemia has been reported, and normally good results have been reported with phosphate replacement. ${ }^{36,37}$

\section{Renal manifestations}

Dehydration, volume depletion, renal hypoperfusion, and decreased intracellular tubular phosphate content often occur. Therefore, signs of renal tubular cell damage, as indicated by increased urinary excretion of enzymes from the brush border membrane such as increased urinary excretion of $\beta_{2}$-microglobulin, $\gamma$-glutamyltransferase, leucine aminopeptidase, and N-acetyl- $\beta$-D-glucosaminidase, are common. Cases of renal tubular acidosis have also been seen. ${ }^{38-40}$ These tubular cell disturbances may occur despite normal glomerular function.

\section{Gastrointestinal manifestations}

Nonspecific hyperamylasemia and abdominal pain are frequent findings during and after treatment of DKA with significantly negative correlation with plasma $\mathrm{Pi}^{41-43}$ In a study of 12 patients with ketoacidosis, salivary, pancreatic isoamylases, and pancreas lipase were determined. Hyperamylasemia was present in six patients, of which, five showed simultaneous increases in all three specific pancreatic enzymes, and one had increased salivary isoamylases alone. In none of the patients, the clinical course or the timeconcentration curves of pancreatic enzymes were consistent with acute pancreatitis. ${ }^{43}$

\section{Discussion}

Despite the prevalence of hypophosphatemia, the aforementioned acute clinical consequences are not common. Some of the cited references are from the period prior to the advent of routine, low-dose insulin administration. However, as indicated, the early and severe hypophosphatemia associated with the recovery phase of DKA seems to be related to rapid uptake of glucose and $\mathrm{Pi}$ by the insulin-sensitive cells and tissues following the administration of insulin and correction of acidosis. In this situation, the insulin-insensitive cells may continue to be phosphate-starved and may suffer from affinity hypoxia with associated metabolic consequences. A flowchart indicating the most important factors leading to ATP deficiency in and during recovery from DKA is presented in Figure 2. Acidosis induces low red cell 2,3-DPG because of inhibition of phosphofructokinase and dehydration. Through redistribution of regional microcirculation and shunt flow, ischemic hypoxia may develop, which can be curtailed by rehydration.

As insulin begins to normalize glucose metabolism in the insulin-sensitive tissues, phosphorus enters into the cells and marked hypophosphatemia may develop. Hypophosphatemia slows the abolishment of affinity hypoxia (Figure 1). The two important elements, phosphorus and oxygen, for optimal ATP synthesis may thereby be limiting factors. Following the initial treatment of DKA, the cells of many organs and tissues may release enzymes, most likely because of this inhibition of energy metabolism. The resulting ATP depletion may lead to fluxes of $\mathrm{Na}^{+}, \mathrm{K}^{+}$, and $\mathrm{Cl}^{-}$according to their gradients across the cellular membranes and with swelling of cells. Subsequently, $\mathrm{Ca}^{2+}$ may leak into the cells, activating phospholipases and the formation of eicosanoids, affecting the cytoskeleton, and initiating oxidant formation. The precise "point of no return" is unknown, but uncontrolled $\mathrm{Ca}^{2+}$ activity in the cell probably has an important role in initiating irreversible cell damage. ${ }^{44}$

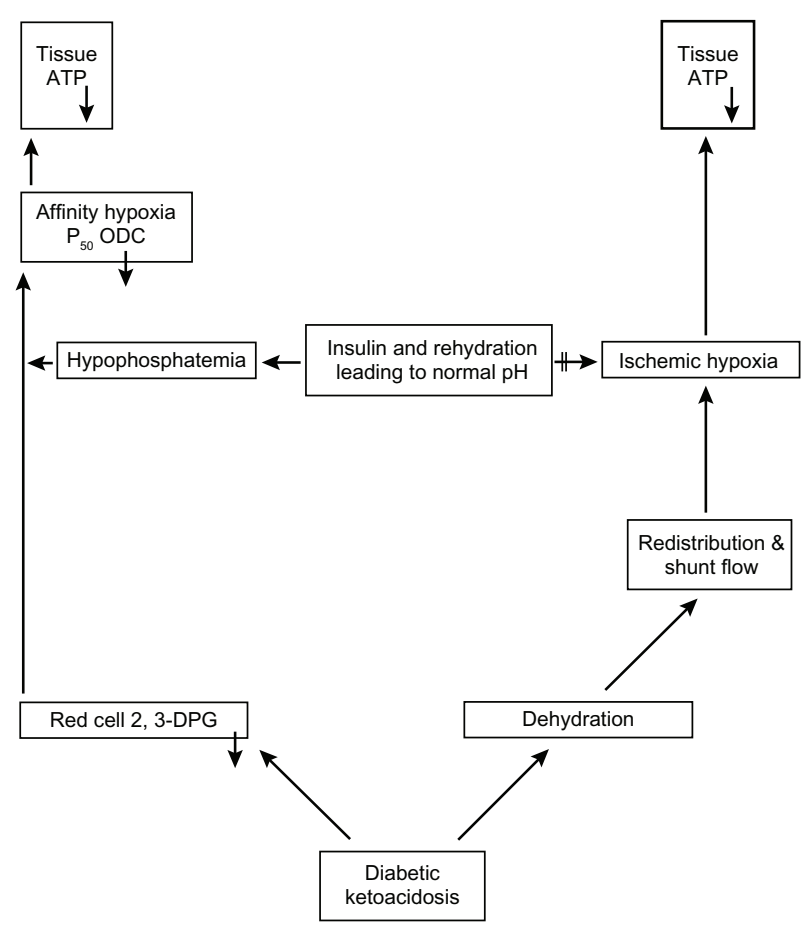

Figure 2 A flowchart indicating the most important factors leading to ATP deficiency in and during recovery from diabetic ketoacidosis.

Abbreviations: ATP, adenosine triphosphate; ODC, oxyhemoglobin dissociation curve; 2,3-DPG, 2,3-diphosphoglycerate. 
Diabetic patients with clinical symptoms of phosphate depletion and severe hypophosphatemia $(<1.0 \mathrm{mg} / \mathrm{dL})$; (tetany, seizures, prolonged unconsciousness, rhabdomyolysis, respiratory failure, and ventricular tachycardia) and those with one or more defective oxygen transport mechanisms (severe anemia, chronic obstructive pulmonary disease, and congestive heart failure) should be repleted with phosphate. The symptoms and signs of phosphate depletion can vary, are nonspecific, and are usually seen in patients with multiple problems. This makes it difficult to identify phosphate depletion as the cause of the clinical manifestations. ${ }^{45}$ The response to phosphorus repletion with solutions of $\mathrm{Pi}$ is usually effective and safe. ${ }^{46}$ The organic phosphate, fructose 1,6-diphosphate (FDP), a key intermediate in glycolysis and the product of the major regulatory enzyme in the pathway (phosphofructokinase), has been suggested as an alternative. FDP acts as human bioenergy and can transport phosphorous into cells and, in a single report, FDP was shown to be more effective and safe than plasma $\mathrm{Pi}$ in restoring red cell 2,3DPG in patients. ${ }^{47}$ Further studies on this subject are clearly needed before any conclusion can be reached.

\section{Disclosure}

The authors report no conflicts of interest in this work.

\section{References}

1. Bloom WL, Flinchum D. Osteomalacia with pseudofractures caused by ingestion of aluminum hydroxide. JAMA. 1960;174(10):1327-1330.

2. Lotz M, Zisman E, Bartter FC. Evidence for a phosphorus-depletion syndrome in man. N Engl J Med. 1968;278(8):409-415.

3. Knochel JP. The pathophysiology and clinical characteristics of severe hypophosphatemia. Arch Intern Med. 1977;137(2):203-220.

4. Kreusser W, Ritz E, Boland R. Phosphat-depletion. Klin Wochenschr. 1980;58(1):1-15.

5. Amanzadeh J, Reilly RF. Hypophosphatemia: an evidence-based approach to its clinical consequences and management. Nat Clin Pract Nephrol. 2006;2(3):136-148.

6. Ditzel J, Lervang HH. Disturbance of inorganic phosphate metabolism in diabetes mellitus: temporary therapeutic intervention trials. Diabetes Metab Syndr Obes. 2009;2:173-177.

7. Ditzel J, Lervang HH. Disturbance of inorganic phosphate metabolism in diabetes mellitus: its impact on the development of diabetic late complications. Curr Diabetes Rev. 2010;6(5):323-333.

8. Riley MS, Shade DS, Eaton RP. Effects of insulin injection on plasma phosphate in diabetic patients. Metabolism. 1979;28(3):191-194.

9. Farber E. ATP and cell integrity. Fed Proc. 1973;32(4):1534-1539.

10. Keller U, Berger W. Prevention of hypophosphatemia by phosphate infusion during treatment of diabetic ketoacidosis and hyperosmolar coma. Diabetes. 1980;29(2):87-94.

11. Wilson HK, Keuer SP, Scott Lea A, Boyd AE III, Eknoyan G. Phosphate therapy in diabetic ketoacidosis. Arch Intern Med. 1982;142(3): 517-520.

12. Becker D, Brown DE, Steranka BH, Drash AL. Phosphate replacement during treatment of diabetic ketosis. Am J Dis Child. 1983;137(3):241-246.

13. Fisher JN, Kitabchi AE. A randomized study of phosphate therapy in the treatment of diabetic ketoacidosis. J Clin Endocrinol Metab. 1983;57(1):177-180.
14. Wolfdorf J, Glasser N, Sperling MA. Diabetic ketoacidosis in infants, children, and adolescents: a consensus statement from American Diabetes Association. Diabetes Care. 2006;29(5):1150-1159.

15. Travis SF, Sugerman HJ, Ruberg R, et al. Alterations of red-cell glycolytic intermediates and oxygen transport as a consequence of hypophosphatemia in patients receiving intravenous hyperalimentation. N Engl J Med. 1971;285(14):763-768.

16. Sheldon GF, Grzyb S. Phosphate depletion and repletion: relation to parenteral nutrition and oxygen transport. Ann Surg. 1975;182(6): 683-689.

17. Lichtman MA, Miller DR. Erythrocyte glycolysis, 2,3-diphosphoglycerate and adenosine triphosphate concentration in uremic subjects: relationship to extracellular phosphate concentration. J Lab Clin Med. 1970;76(2):267-279.

18. Bellingham AJ, Detter JC, Lenfant C. The role of hemoglobin affinity for oxygen and red cell 2,3-DPG in the management of diabetic ketoacidosis. Trans Assoc Am Physicians. 1970;83:113-120.

19. Alberti KGMM, Emerson PM, Darley JH, Hochaday TD. 2,3-diphosphoglycerate and tissue oxygenation in uncontrolled diabetes. Lancet. 1972;2(7774):391-395.

20. Ditzel J, Standl E. The oxygen transport system of red blood cells during diabetic ketoacidosis and recovery. Diabetologia. 1975;11(4): 255-260.

21. Ditzel J. Problem of tissue oxygenation in diabetes as related to development of diabetic retinopathy. In: Mausoft FA, editor. Eye and Systemic Disease. Saint Louis, Toronto. London: C.V. Mosby Company; 1980. p.179-186.

22. Shilo P, Werner D, Hershko C. Acute hemolytic anemia caused by severe hypophosphatemia in diabetic ketoacidosis. Acta Haematol. 1985;73(1):55-57.

23. Chinn RY, Diamond RD. Generation of chemotactic factors by Rhizopus aryzae in the presence or absence of serum: relationship to hyphal damage mediated by human neutrophils and effects of hyperglycemia and ketoacidosis. Infect Immun. 1982;38(2):1123-1129.

24. Franks M, Berris RF, Kaplan NO, Myers GB. Metabolic studies in diabetic acidosis; Part II: the effect of the administration of sodium phosphate. Arch Intern Med. 1948;81(1):42-55.

25. Ditzel J. Effect of plasma inorganic phosphate on tissue oxygenation during recovery from diabetic ketoacidosis. Adv Exp Med Biol. 1973; 37A:163-172.

26. Megarbane B, Guerrier G, Blanche A, Meas T, Guillanestau PJ, Baud FJ. A possible hypophosphatemia-induced, life-threatening encephalopathy in ketoacidosis: a case report. Am J Med Sci. 2007;333(6):384-386.

27. de Oliveira Iglesias SB, Pons Leite H, de Carvalho WB. Hypophosphatemia-induced seizure in a child with diabetic ketoacidosis. Pediatr Emerg Care. 2009;25(12):859-861.

28. Singhal PC, Kumar A, Desroches L, Gibbons N, Mattana J. Prevalence and predictors of rhabdomyolysis in patients with hypophosphatemia. Am J Med. 1992;92(5):458-464.

29. Møller-Petersen J, Thorgaard Andersen P, Hjørne N, Ditzel J. Nontraumatic rhabdomyolysis during diabetic ketoacidosis. Diabetologia. 1986;29(4):229-234.

30. Ditzel J, Standl E. The problem of tissue oxygenation in diabetes mellitus; Part II: evidence of disordered oxygen release from the erythrocytes in diabetics in various conditions of metabolic control. Acta Med Scand. 1975;197 Suppl 578:S49-S58.

31. Christensen NJ. Plasma noradrenaline and adrenaline measured by isotope-derivative assay. A review with special reference to diabetes mellitus. Dan Med Bull. 1979;26(1):17-36.

32. Ditzel J, Sargeant L, Hadley WB. The relationship of abnormal vascular responses to retinopathy and nephropathy in diabetics. Arch Intern Med. 1958;101(5):912-920.

33. Møller N, Foss AC, Gravholt CH, Mortensen UM, Poulsen SH, Mogensen CE. Myocardial injury with biomarker elevation in diabetic ketoacidosis. J Diabet Complications. 2005;19(6):361-363.

34. O'Connor LR, Wheeler WS, Bethune JE. Effect of hypophosphatemia on myocardial performance in man. N Engl J Med. 1977;297(17): 901-903. 
35. Darsee JR, Nutter DO. Reversible severe congestive cardiomyopathy in three cases of hypophosphatemia. Ann Intern Med. 1978;89(6): $867-870$.

36. Hasselstrøm L, Wimberley PD, Nielsen VG. Hypophosphatemia and acute respiratory failure in a diabetic patient. Intensive Care Med. 1986; 12(6):429-431.

37. Liu PY, Jeng CY. Severe hypophosphatemia in a patient with diabetic ketoacidosis and acute respiratory failure. J Chin Med Assoc. 2004; 67(7):355-359.

38. Miltenyi M, Körner A, Tulassay T, Szabo A. Tubular dysfunction in type I diabetes mellitus. Arch Dis Child. 1985;60(10):929-931.

39. Miltenyi M, Szabo A, Tulassay T, Körner A, Kenesei E, Dobos M. Reduced glomerular filtration and elevated urinary protein excretion in diabetic ketoacidosis. Acta Paediatr Scand. 1990;79(4):444-447.

40. Guammarco R, Goldstein MB, Halperin ML, Stinebaugh BJ. Renal tubular acidosis during therapy for diabetic ketoacidosis. Can Med Assoc J. 1975;112(4):463-466.

41. Yadav D, Nair S, Norkus EP, Pitchumoni CS. Nonspecific hyperamylasemia and hyperlipasemia in diabetic ketoacidosis: incidence and correlation with biochemical abnormalities. Am J Gastroenterol. 2000;95(11):3123-3128.
42. Kjærgaard JJ, Salling N, Magid E, Ditzel J. Serum amylase during recovery from diabetic ketoacidosis. Diabete Metab (Paris). 1984;10(1): 25-30.

43. Møller-Petersen J, Andersen PT, Hjørne N, Ditzel J. Hyperamylasemia, specific pancreatic enzymes, and hypoxanthine during recovery from diabetic ketoacidosis. Clin Chem. 1985;31(12):2001-2004.

44. Kristensen SR. Mechanisms of cell damage and enzyme release. Dan Med Bull. 1994;41(4):423-433.

45. Berner YN, Shike M. Consequences of phosphate imbalance. Annu Rev Nutr. 1988;8:121-148.

46. Vannatta JB, Whang R, Papper S. Efficacy of intravenous phosphorus therapy in the severely hypophosphatemic patient. Arch Intern Med. 1981;141(7):885-887.

47. Iapichino G, Radrizzani D, Solca M, et al. Restoration of blood 2,3-diphosphoglycerate levels in multitransfused patients: effect of organic and inorganic phosphate. Int Surg. 1984;69(2):113-116.

\section{Publish your work in this journal}

Diabetes, Metabolic Syndrome and Obesity: Targets and Therapy is an international, peer-reviewed open-access journal committed to the rapid publication of the latest laboratory and clinical findings in the fields of diabetes, metabolic syndrome and obesity research. Original research, review, case reports, hypothesis formation, expert opinion and commentaries are all considered for publication. The manuscript management system is completely online and includes a very quick and fair peer-review system, which is all easy to use. Visit http://www.dovepress.com/testimonials.php to read real quotes from published authors.

Submit your manuscript here: http://www.dovepress.com/diabetes-metabolic-syndrome-and-obesity-targets-and-therapy-journal 